\title{
Higher Prevalence of Diabetes Mellitus and Impaired Glucose Tolerance Among the Rural Population in Bulgaria
}

\author{
Anna-Maria Borissova ${ }^{\mathrm{a}, \mathrm{b}}$, Alexander Shinkova ${ }^{\mathrm{a}}$, Jordan Vlahov ${ }^{\mathrm{a}}$, Lilia Dakovska ${ }^{\mathrm{a}}$, \\ Todor Todorov ${ }^{\mathrm{a}}$
}

\begin{abstract}
Background: The socio-economic level is probably among the central risk factors for type 2 diabetes mellitus (T2DM) along with obesity, decreased physical activity and smoking. The International Diabetes Federation notes in particular that the main impact in the prevalence of diabetes is observed in low and middle-income countries, hence the disease might disproportionately affect lower socioeconomic groups. The aim of the study was to determine the prevalence of diabetes and impaired glucose tolerance (IGT) and assess its association with the type of place of residence in Bulgaria - cities, small towns and villages.
\end{abstract}

Methods: We surveyed 2,032 subjects from five major geographic regions of the country, with age and gender proportions according to the latest population census $-27.5 \%$ rural population and $72.5 \%$ urban population. We included 1,076 women (53\%) and 956 men (47\%), with a mean age of $49.3 \pm 14.8$ years (20 - 80 years). Fasting blood glucose was measured in all participants and when indicated oral glucose tolerance test was performed. Diabetes was defined according to the WHO criteria (1999).

Results: The prevalence of known T2DM, previously unknown T2DM and IGT was significantly higher among the rural population than in the city population - known T2DM: $8.6 \%$ (46/535) vs. $6 \%$ (62/1,031), P < 0.02; previously unknown T2DM: 3.55\% (19/535) vs. $1.74 \%$ (18/1,031), P < 0.02; IGT: $2.4 \%$ (13/535) vs. $1.1 \%(12 / 1,031)$, $\mathrm{P}<0.04$. The combined prevalence of diabetes (known and unknown) and IGT (impaired fasting glucose (IFG) + IGT) was $16.44 \%(88 / 535)$ in the rural population, $14.13 \%(66 / 467)$ (NS) in small towns, and $11.16 \%$ in cities $(115 / 1,030)(\mathrm{P}<0.01)$.

Conclusions: National screening programs for diabetes should focus on the rural population due to the higher diabetes prevalence that

Manuscript accepted for publication March 24, 2016

a'Medical University of Sofia, University Hospital of Endocrinology, 2 Zdrave St, Sofia 1431, Bulgaria

${ }^{b}$ Corresponding Author: Anna-Maria Borissova, Department of Thyroid and Metabolic Bone Disorders, University Hospital of Endocrinology, 2 Zdrave St, Sofia 1431, Bulgaria. Email: anmarbor@abv.bg

doi: http://dx.doi.org/10.14740/jem334w might be explained by multiple adverse socio-economic factors.

Keywords: Diabetes mellitus; Diabetes prevalence; Impaired glucose tolerance; Rural population; Urban population

\section{Introduction}

The number of subjects with diabetes has doubled globally in the recent three decades, which makes the disorder a major health problem worldwide [1]. The national surveys on diabetes offer neither stratified prevalence by urban and rural population nor estimation of the urban/rural ratio. The United Nations Population Division 2010 has proposed specific formulae for the calculation of the urban population in the different countries [2].

Socio-economic difficulties are associated with a deterioraton in the health care conditions, a decrease in the life expectancy and an increased morbidity [3]. The socio-economic background affects the health of the individual subject both depending on his/her financial situation and through the health care system's will to execute effective screening programs for early detection and prevention of chronic disorders. The International Diabetes Federation (IDF) stressed that the major impact of the increase in diabetes morbidity will affect the countries with low and medium income and will disproportunately affect the low-income social groups [4]. A two-fold higher diabetes prevalence was reported among the Australian populations from poorer regions (5\%) than among those from more affluent ones (2\%) [4].

Another interesting observation concerns the variation in diabetes prevalence between urban and rural populations. No difference has been reported for the developed countries, but diabetes is twice as prevalent in the urban areas as in the rural ones in the developing countries $[5,6]$.

Mohan et al described higher diabetes prevalence in the lower socio-economic groups in the developed countries and in the higher socio-economic groups in the developing countries [7]. That observation might reflect the healthier lifestyle among the highly educated groups in the developed countries and the lower physical activity and overindulging with highcalorie nutrition among the rich in the developing countries $[8,9]$. 
Table 1. Distribution of the Participants According to the Place of Residence, Gender and Age Group

\begin{tabular}{ll|}
\hline $\begin{array}{l}\text { Place of residence } \\
\text { Town }\end{array}$ & Number (\%) \\
\hline Small town & $1,030(50.6 \%)$ \\
Village & $467(23.1 \%)$ \\
Age group & $535(26.3 \%)$ \\
Female & \\
$20-44$ years & $446(41.5 \%)$ \\
$45-59$ years & $281(26.1 \%)$ \\
60 and older & $349(32.4 \%)$ \\
Male & \\
$20-44$ years & $448(46.8 \%)$ \\
$45-59$ years & $253(26.5 \%)$ \\
60 and older & $255(26.7 \%)$ \\
\hline
\end{tabular}

Some authors have reported that the social group is a major risk factor for type 2 diabetes, similarly to obesity, low physical activity and smoking [3]. Last but not least, the personal socio-economic status seems just as important - residence in a poorer area with high unemployment rate and poor infrastructure is associated with a higher risk of diabetes. Some other potential factors that might contribute to the regional differences in diabetes prevalence have been identified recently. Examples of such factors associated with insulin resistance and diabetes include air pollution, high noise levels, the lack of recreation and sports areas and the variations in health care $[3,10]$. Some individual characteristics are important as well: smoking, alcohol abuse, and a sedentary lifestyle.

The aim of the present work was to assess the prevalence of diabetes and impaired glucose tolerance (IGT) as a function of the place of residence - city, small town and village. The initial assumption was that the differences in health care might determine possible differences in the observed prevalence.

\section{Materials and Methods}

The study was designed as a cross-sectional survey and was carried out in 12 regions. Three thousand four hundred and fifty subjects 20 years or older from both genders were invited to participate. Two thousand thirty-two subjects agreed to be enrolled (58.8\%) and signed an informed consent, approved by the local Ethics Committee at the University Hospital of Endocrinology in Sofia. All participants filled in a questionnaire including questions on demographic data, current health, past health history, family history for hypertension, diabetes, thyroid and chronic kidney disease, current and past medication, smoking, and menstrual status for the female participants. Body weight, height and waist circumference (WC) were measured and the body mass index (BMI) was calculated by the standard formula. Arterial blood pressure was measured in
Table 2. Educational Level for the Total Population, the Urban and the Rural Population in the Country - 2011 Population Census [11]

\begin{tabular}{llll}
\hline Educational level & Total for the country & Urban & Rural \\
\hline University & $19.6 \%$ & $24.8 \%$ & $5.8 \%$ \\
Secondary & $43.4 \%$ & $48.7 \%$ & $34.5 \%$ \\
Elementary & $23.1 \%$ & $17.5 \%$ & $37.8 \%$ \\
Primary & $7.8 \%$ & $5.6 \%$ & $13.5 \%$ \\
No level completed & $6.2 \%$ & $5.3 \%$ & $8.3 \%$ \\
\hline
\end{tabular}

the sitting position after a 5 -min rest. Fasting venous blood samples were taken between 7 and 9:00 am. Two subjects refused the venipuncture and were subsequently excluded.

\section{Design}

The studied subjects represented five major geographic regions: 1) Northwestern (Vidin, Dunavtzi, Montana, Troyan and the adjacent villages) - 431 participants, $21.2 \%$ of the cohort; 2) Northeastern (Dobrich, Russe, Byala and the adjacent villages) - 454 participants, $22.3 \%$ of the cohort; 3) Southeastern (Sliven, Stara Zagora and the adjacent villages) - 384 participants, $18.9 \%$ of the cohort; 4) Southwestern (Blagoevgrad, Sandanski and the adjacent villages) - 406 participants, $20 \%$ of the cohort; 5) Central western (Sofia and the adjacent villages) - 357 participants, $17.6 \%$ of the cohort.

A thousand and seventy-six females (53\%) and 956 males $(47 \%)$, with a mean age of $49.3 \pm 14.8$ years (20 - 80 years) participated, subdivided into three age groups (Table 1). The participant distribution by region, gender and age was determined in accordance with the population distribution, described by the National Statistical Institute (NSI) after the latest census in 2011 (Table 1) [11]. The latest NSI census shows that $73.5 \%$ of the urban and $40.3 \%$ of the rural population has higher or secondary education and $59.6 \%$ of the rural population has elementary, primary or no completed educational level (Table 2).

\section{Methods}

Venous blood samples were collected between 7 and 9 am after an overnight fast. Plasma glucose was measured by an automated glucose-oxidase analyzer (Glucose Analyzer II, Beckman, USA) and all samples were processed by a single laboratory technician. The daily calibration and quality control were performed as per the manufacturer recommendations with standards Presinorm (Roche) - glucose $4.9 \pm 0.3 \mathrm{mmol} / \mathrm{L}$ and Presipath (Roche) - glucose $12.6 \pm 0.5 \mathrm{mmol} / \mathrm{L}$.

Fasting blood glucose was accepted as normal if $\leq 6.0$ $\mathrm{mmol} / \mathrm{L}$. Diabetes was diagnosed in all subjects without a history of known diabetes after the WHO 1999 criteria when fasting glucose $\geq 7.0 \mathrm{mmol} / \mathrm{L}$ was measured $[12,13]$. A standard oral glucose tolerance test (OGTT - a measurement at $120 \mathrm{~min}$ after a $75 \mathrm{~g}$ glucose load) was performed in subjects with fasting glucose $6.1-6.9 \mathrm{mmol} / \mathrm{L}$ and in those with fasting glucose 
Table 3. The Prevalence of the Known and Newly Diagnosed Diabetes, IFG and IGT by Age, Gender and Place of Residence

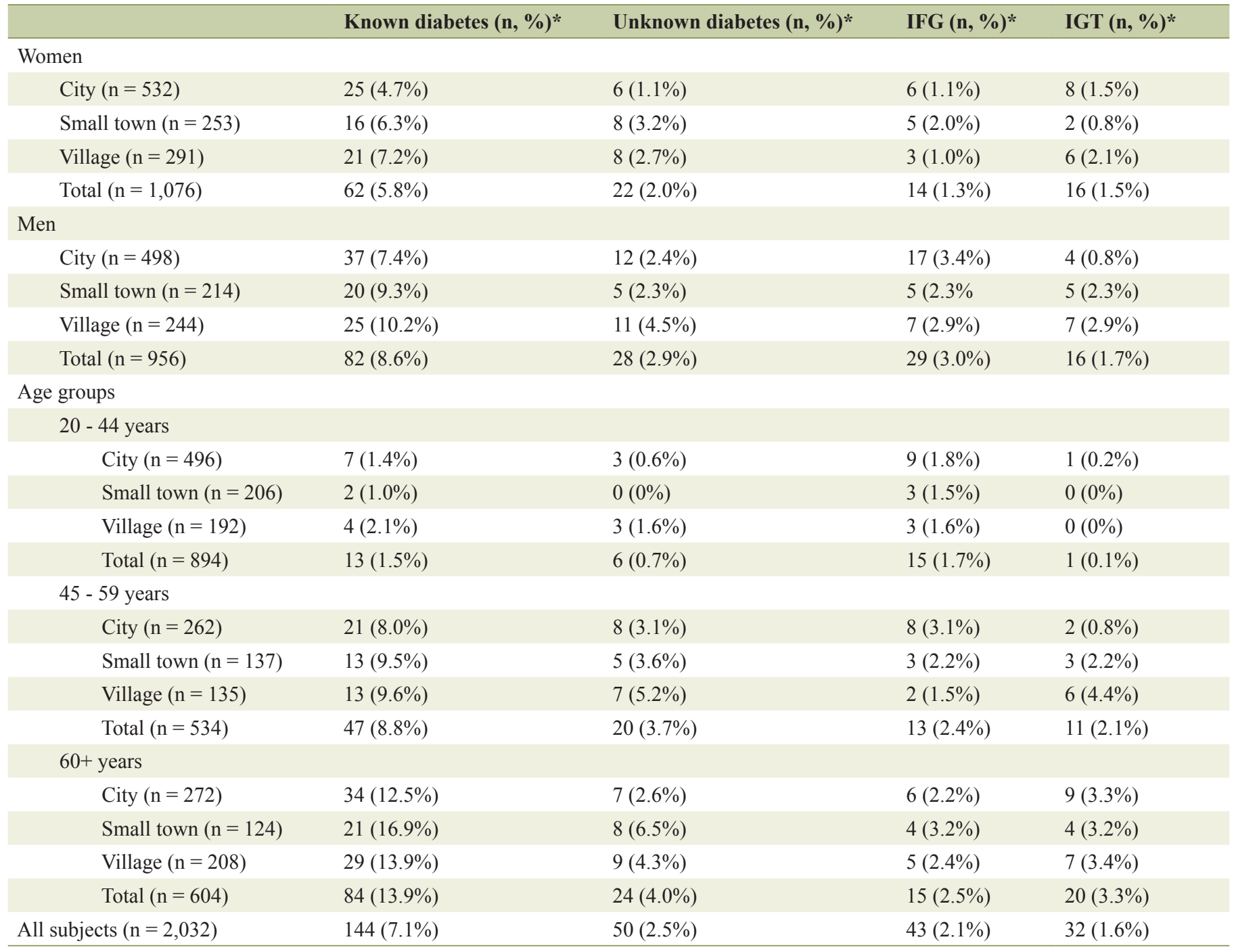

*Proportion of the respective place of residence.

equal to $7.0 \mathrm{mmol} / \mathrm{L}$. OGTT was done in 97 subjects $(4.77 \%$ of the 2,032). Two subjects refused the OGTT. The measurements were interpreted as follows: 1) IGT: 120 min glucose 7.8 - $11.0 \mathrm{mmol} / \mathrm{L}$; 2) impaired fasting glucose (IFG): fasting glucose $6.1-6.9 \mathrm{mmol} / \mathrm{L}$ and $120 \mathrm{~min}$ glucose $<7.8 \mathrm{mmol} / \mathrm{L}$; 3 ) newly diagnosed diabetes mellitus: fasting plasma glucose $>7.0 \mathrm{mmol} / \mathrm{L}$ or $120 \mathrm{~min}$ glucose $\geq 11.1 \mathrm{mmol} / \mathrm{L}$.

\section{Statistical analysis}

The data were processed with SPSS v.13.0 (SPSS Inc., Chicago, IL). The data were grouped according to the predefined grouping variables and a descriptive analysis was performed. The proportions of the subjects with diabetes, IFG or IGT were calculated for all subgroups and then the expected and observed frequencies were compared by Chi-square. Logistic regression was applied to assess the factors contributing to diabetes prevalence. A P-value $<0.05$ was accepted as statistically significant.

\section{Availability of data and materials}

The dataset supporting the conclusions of this article is available in Open Science Framework at https://osf.io/nrhce/?view_ only $=\mathrm{ab} 13 \mathrm{~d} 94 \mathrm{c} 3 \mathrm{bdc} 442 \mathrm{cb} 40 \mathrm{a} 02 \mathrm{f} 2 \mathrm{e} 3 \mathrm{~d} 7 \mathrm{ec} 01$.

\section{Results}

IFG was found in 43 subjects, IGT in 32 and newly diagnosed diabetes in 50 (27 with fasting plasma glucose $>7.0 \mathrm{mmol} / \mathrm{L}$ and 23 with $120 \mathrm{~min}$ glucose $\geq 11.1 \mathrm{mmol} / \mathrm{L}$ ) (Table 3 ). The total diabetes prevalence was $9.6 \%(194 / 2,032), 7.8 \%$ in the females $(84 / 1,076)$ and $11.5 \%$ in the males $(110 / 956)(\mathrm{P}<0.01)$. 
Table 4. Age and Gender Distribution of the Subjects With Diabetes Mellitus and IFG + IGT According to the Type of Residence

\begin{tabular}{|c|c|c|}
\hline Place of residence, gender, age & Diabetes $(n=194)$ & Impaired glucose tolerance (IFG + IGT) $(n=75)$ \\
\hline City $(\%$ of total $)$ & $80 / 194(41.2 \%)$ & $35 / 75(46.7 \%)$ \\
\hline \multicolumn{3}{|l|}{ Gender } \\
\hline Women & $31(38.7 \% \%)$ & $14(40 \%)$ \\
\hline Men & $49(61.3 \%)$ & $21(60 \%)$ \\
\hline \multicolumn{3}{|l|}{ Age group } \\
\hline $20-44$ years & $10(12.5 \%)$ & $10(28.6 \%)$ \\
\hline $45-59$ years & $29(36.2 \%)$ & $10(28.6 \%)$ \\
\hline $60+$ years & $41(51.3 \%)$ & $15(42.8 \%)$ \\
\hline Small town (\% of total) & $49 / 194(25.3 \%)$ & $17 / 75(22.6 \%)$ \\
\hline \multicolumn{3}{|l|}{ Gender } \\
\hline Women & $24(49 \%)$ & $7(41.2 \%)$ \\
\hline Men & $25(51 \%)$ & $10(58.8 \%)$ \\
\hline \multicolumn{3}{|l|}{ Age group } \\
\hline $20-44$ years & $2(4.1 \%)$ & $3(17.6 \%)$ \\
\hline $45-59$ years & $18(36.7 \%)$ & $6(35.3 \%)$ \\
\hline $60+$ years & $29(59.2 \%)$ & $8(47.1 \%)$ \\
\hline Village ( $\%$ of total) & $65 / 194(33.5 \%)$ & $23 / 75(30.7 \%)$ \\
\hline \multicolumn{3}{|l|}{ Gender } \\
\hline Women & $29(44.6 \%)$ & $9(39.1 \%)$ \\
\hline Men & $36(55.4 \%)$ & $14(60.9 \%)$ \\
\hline \multicolumn{3}{|l|}{ Age group } \\
\hline $20-44$ years & $7(10.8 \%)$ & $3(13 \%)$ \\
\hline $45-59$ years & $20(30.8 \%)$ & $8(34.8 \%)$ \\
\hline $60+$ years & $38(58.4 \%)$ & $12(52.2 \%)$ \\
\hline
\end{tabular}

The prevalence of known diabetes was significantly higher in the rural areas than in the cities $(\mathrm{P}=0.027)$. The total diabetes rates, known and newly diagnosed, followed the same pattern: significantly higher in the rural population $(12.1 \%)$ than in the population in the cities $(7.8 \%)(\mathrm{P}<0.01)$. The rate in the small town was intermediate $(10.5 \%)$ and did not differ significantly from either of the other two groups.

IGT was marginally more prevalent in the villages $(2.4 \%)$ than in the cities $(1.1 \%)(\mathrm{P}=0.048)$, while IFG did not differ among the three groups (all $\mathrm{P}=\mathrm{NS}$ ). The combined prevalence of diabetes and prediabetes was significantly higher among the rural population than in the cities, $16.44 \%$ vs. $11.2 \%(\mathrm{P}<$ $0.01)$, with no difference with the small towns $(14.1 \%)$.

The prevalence of the IFG and IGT demonstrated a dependence on the place of residence (Table 4). Despite the fact that $27.5 \%$ of the population lives in the villages (NSI 2011), we found $33.7 \%$ of the subjects with diabetes among the rural population. Furthermore, the proportion of diabetic males

Table 5. Age and Gender Distribution of the Subjects With Diabetes - Known or Newly Diagnosed

\begin{tabular}{llll}
\hline Groups & Known diabetes $(\mathbf{n}=\mathbf{1 4 4}, \mathbf{7 4 \%})$ & Unknown diabetes $(\mathbf{n}=\mathbf{5 0 , 2 6 \% )}$ & Total $(\mathbf{n}=\mathbf{1 9 4})$ \\
\hline \begin{tabular}{lll} 
Gender \\
\multicolumn{1}{c}{ Women }
\end{tabular} & $62 / 144(43 \%)$ & $22 / 50(44 \%)$ & $84 / 194(43.3 \%)$ \\
Men & $82 / 144(57 \%)$ & $28 / 50(56 \%)$ & $110 / 194(56.7 \%)$ \\
Age group & & & $19 / 194(9.8 \%)$ \\
$20-44$ years & $13 / 144(9.1 \%)$ & $6 / 50(12 \%)$ & $67 / 194(34.5 \%)$ \\
$45-59$ years & $47 / 144(32.6 \%)$ & $20 / 50(40 \%)$ & $108 / 194(55.7 \%)$ \\
\hline
\end{tabular}


to females was significantly higher in the cities $(61.3 \%$ and $38.7 \%$ ) than in the small towns and villages $(51 \%$ and $49 \%$; $44.6 \%$ and $51 \%)(\mathrm{P}<0.05)$. Both diabetes and IFG/IGT increased with age irrespective of the place of residence.

The proportion of previously unknown diabetes was slightly higher in the younger with no gender difference (Table 5).

A logistic regression model including the age, gender, BMI, WC, education level, place of residence and smoking status as factors and diabetes as a dependent variable was performed. The only significant factors were the age - the age over 45 years was associated with an OR 7.3 (4.4 - 11.9); and the $\mathrm{WC}$ - each centimeter increase in the WC was associated with a $5 \%(4-6)$ increase in the probability of having diabetes. The place of residence, the education or gender did not influence significantly the regression model.

\section{Discussion}

We found a significantly higher prevalence of previously known diabetes in the villages as compared to the cities $(8.6 \%$ vs. $6 \%, \mathrm{P}=0.027)$. The figures for the small towns fell in between $(7.7 \%)$. The prevalence of the newly diagnosed diabetes showed a similar trend: twice as high in the rural areas as in the cities $(3.6 \%$ vs. $1.7 \%, \mathrm{P}=0.025)$. The analysis of the prediabetes - IFG and IGT yielded similar results for the IGT, but not the IFG (Table 5). Therefore, a gradient in the diabetes and prediabetes prevalence both separately and summed together was observed, sloping up from smaller to larger place of residence. In fact, we observed a disproportionately higher diabetes rates to the urban to rural population distribution in the villages. Our results offered some confirmation to the hypothesis of Connollya et al who studied hospital and primary care documentation, and identified 4,313 subjects with diabetes among a population of 287,157 . The authors proposed the hypothesis that an inverse correlation existed between diabetes and socioeconomic class [14]. They found high diabetes prevalence in the poorer regions, and particularly in the age 40 - 69 years.

One possible explanation might lie in the differences in health care. Both the access to specialized and tertiary care and the extent of preventive programs are usually better in the large cities. The fact that the education level correlates with the participation in preventive programs and the compliance with the recommendations in diabetic subjects has been reported by other authors [15]. Thus, lower education affects subjects' attitude towards such activities and might also be related to an underestimation of personal health risks. A typical example is a phenomenon that some authors have described as psychological insulin resistance (PIR). Machinani et al observed a higher rate of unwillingness to insulin treatment initiation in low-income, low-education diabetic subjects [16]. The proportion of the subjects with completed secondary and higher education in Bulgaria is almost two-fold lower in the rural areas, than in the urban, as is seen in Table 2. This should be born in mind when determining the target population groups for community-based prevention programs [17].

Other factors closely related to both education and health care are the socio-economic status and the employment. Unemployment has risen in the Bulgarian villages after the disintegration of state-regulated farming over the past three decades. The unemployment rate in the villages is currently 1.5-fold higher than in the urban areas $[11,18]$. Unemployed subjects and low-income groups often have suspended medical insurance. Private health care is expensive and the result is a neglect of most medical non-emergencies. The authors of two other studies reach similar conclusions, linking the diabetes prevalence to regional social and economic factors including unemployment $[19,20]$. They observed higher diabetes prevalence with increasing unemployment rate. Green et al found further association between diabetes distribution and some indices of low socio-economic status, environment pollution and unhealthy lifestyle [21].

An interesting approach was taken by Maier et al [22]. They studied the association in a large sample of German population of the prevalence of diabetes and obesity with a complex factor: area level deprivation. The latter was assessed by the German index of multiple deprivation (GIMP) which comprises several domains of deprivation: income, education, employment, municipal revenue, social capital, environment and security. The authors observed that a higher level of area deprivation was associated with a higher prevalence of diabetes and obesity, independently of the education or other personal risk factors. Our findings lead to similar conclusions, though we did not include a comparable measurement tool in our study. The regression model however suggested that obesity as measured by the WC was a major contributor to the diabetes prevalence. Furthermore, we observed an inverse relationship of the WC with the education level with lower figures among the university graduates and higher in the subjects with elementary school degree (unpublished data). Therefore, it might be speculated that lower education level and lower socio-economic class lead to higher abdominal obesity through poorer dietary habits - higher fat, carbohydrate and junk food intake, less exercising and lower awareness of the health outcomes of obesity.

Some additional risk factors might be suspected to play a role for the observed results. Alcohol consumption, smoking and decreased physical activity increase with unemployment, low income and lower education level. As a result, chronic morbidity also rises. It might be presumed that diabetes is only one of the possible adverse outcomes - the life expectancy tables for the Bulgarian population show approximately 2 years shorter life expectancy for the rural than the urban population [11].

The regression model however suggested that the place of residence lost its significance as a predictor of diabetes when the model controlled for age and abdominal obesity as measured by the WC. A more complex association with an interplay of multiple factors might be presumed.

Our study has certain limitations. First of all, the questionnaire model of data collection cannot guarantee the accuracy of the responder-filled information. We believe that an underreporting of risk factors exists. Therefore, other tools such as primary care registry analysis would be advantageous. Furthermore, only 41 subjects in our study reported being currently unemployed. Our opinion is that the unexpectedly low 
number is the result of underreporting; therefore, we decided not to use the data.

\section{Conclusion}

In conclusion, we observed a significantly higher diabetes prevalence among the rural population, probably as a result of the interaction of multiple and complex social, personal and health care factors. Therefore, the rural population should be specifically targeted in future diabetes prevention and early detection programs. Further research on a wider range of risk factors might throw more light on the complex mechanisms underlying the observed associations.

\section{Acknowledgement}

We would like to thank the following collaborators for the valuable support: E. Dimitrova (Vidin), J. Stoyanova (Montana), V. Yotova (Troyan), R. Bobeva, A. Momcheva, V. Subev (Sliven), J. Gerenova (Stara Zagora), P. Velkova, D. Zhekova (Dobrich), B. Savova, A. Kiselova (Russe), V. Margaritov (Byala), T. Kotzelova (Blagoevgrad), K. Anastasov (Sandanski), and K. Kalinov; and the technical staff: A. Popov, G. Mihailov, K. Pantcheva, G. Antalavitcheva, T. Kornilova, S. Mihailova, B. Petrovska, E. Blajeva, I. Kassabova, and A. Palamarev.

\section{Conflicts of Interest}

None.

\section{Funding}

The study was supported financially by the Bulgarian Society of Endocrinology with the sponsorship of Aquachim, Roche Bulgaria, Eli Lilly/Boehringer Ingelheim, Amgen, MSD, Merck Serono, Servier, Novartis, Berlin-Chemie.

\section{References}

1. Chen L, Magliano DJ, Zimmet PZ. The worldwide epidemiology of type 2 diabetes mellitus--present and future perspectives. Nat Rev Endocrinol. 2012;8(4):228-236.

2. United Nations. World population prospects: the 2010 revision. Geneva: United Nations, 2011.

3. Maier W, Holle R, Hunger M, Peters A, Meisinger C, Greiser KH, Kluttig A, et al. The impact of regional deprivation and individual socio-economic status on the prevalence of Type 2 diabetes in Germany. A pooled analysis of five population-based studies. Diabet Med. 2013;30(3):e78-86.

4. A Snapshot, 2007-08. Diabetes in Australia. 2011, Canberra.

5. King H, Aubert RE, Herman WH. Global burden of dia- betes, 1995-2025: prevalence, numerical estimates, and projections. Diabetes Care. 1998;21(9):1414-1431.

6. Finucane MM, Stevens GA, Cowan MJ, Danaei G, Lin JK, Paciorek CJ, Singh GM, et al. National, regional, and global trends in body-mass index since 1980: systematic analysis of health examination surveys and epidemiological studies with 960 country-years and 9.1 million participants. Lancet. 2011;377(9765):557-567.

7. Mohan V, Shanthirani S, Deepa R, Premalatha G, Sastry $\mathrm{NG}$, Saroja R. Intra-urban differences in the prevalence of the metabolic syndrome in southern India -- the Chennai Urban Population Study (CUPS No. 4). Diabet Med. 2001;18(4):280-287.

8. Shaw JE, Chisholm DJ. 1: Epidemiology and prevention of type 2 diabetes and the metabolic syndrome. Med J Aust. 2003;179(7):379-383.

9. Rathmann W, Scheidt-Nave C, Roden M, Herder C. Type 2 diabetes: prevalence and relevance of genetic and acquired factors for its prediction. Dtsch Arztebl Int. 2013;110(19):331-337.

10. Kramer U, Herder C, Sugiri D, Strassburger K, Schikowski T, Ranft U, Rathmann W. Traffic-related air pollution and incident type 2 diabetes: results from the SALIA cohort study. Environ Health Perspect. 2010;118(9):12731279.

11. 17th National Census. National Statistical Institute, Sofia, 2011. http://www.nsi.bg/census2011/PDOCS2/Census2011final_en.pdf. Accessed 20 Feb 2015.

12. Report of a WHO/IDF Consultation (2006). Definition and Diagnosis and of Diabetes Mellitus and intermediate hyperglycemia, Geneva, WHO. 2006.

13. WHO Definition, diagnosis and classification of Diabetes mellitus and its complications. Geneva, WHO. 1999.

14. Connolly V, Unwin N, Sherriff P, Bilous R, Kelly W. Diabetes prevalence and socioeconomic status: a population based study showing increased prevalence of type 2 diabetes mellitus in deprived areas. J Epidemiol Community Health. 2000;54(3):173-177.

15. Ko KD, Kim BH, Park SM, In Oh S, Um CS, Shin DW, Lee HW. What are patient factors associated with the quality of diabetes care?: results from the Korean National Health and Nutrition Examination Survey. BMC Public Health. 2012;12:689.

16. Machinani S, Bazargan-Hejazi S, Hsia SH. Psychological insulin resistance among low-income, U.S. racial minority patients with type 2 diabetes. Prim Care Diabetes. 2013;7(1):51-55.

17. Chan JC, Zhang Y, Ning G. Diabetes in China: a societal solution for a personal challenge. Lancet Diabetes Endocrinol. 2014;2(12):969-979.

18. Convergence Program of the Republic of Bulgaria 20132016 year. Ministry of Finance. 2013, Sofia, Bulgaria.

19. Mueller G, Berger K. The influence of neighbourhood deprivation on the prevalence of diabetes in 25- to 74-year-old individuals: first results from the Dortmund Health Study. Diabet Med. 2012;29(6):831-833.

20. Muller G, Kluttig A, Greiser KH, Moebus S, Slomiany U, Schipf S, Volzke H, et al. Regional and neighborhood disparities in the odds of type 2 diabetes: results from 5 
population-based studies in Germany (DIAB-CORE consortium). Am J Epidemiol. 2013;178(2):221-230.

21. Green C, Hoppa RD, Young TK, Blanchard JF. Geographic analysis of diabetes prevalence in an urban area. Soc Sci Med. 2003;57(3):551-560.

22. Maier W, Scheidt-Nave C, Holle R, Kroll LE, Lampert
T, Du Y, Heidemann C, et al. Area level deprivation is an independent determinant of prevalent type 2 diabetes and obesity at the national level in Germany. Results from the National Telephone Health Interview Surveys 'German Health Update' GEDA 2009 and 2010. PLoS One. 2014;9(2):e89661. 